\title{
Autodeterminação informativa: a história de um conceito
}

\author{
The Right to Information Self-Determination: a History of a Concept
}

\author{
Laura Schertel Ferreira Mendes*
}

\section{Resumo}

Nos debates sobre proteção de dados pessoais, o direito à autodeterminação informativa representa uma das expressões mais conhecidas. O conceito é relevante não apenas na Alemanha, mas também influenciou diversos ordenamentos estrangeiros, tendo sido incorporado como um dos fundamentos da Lei Geral de Proteção de Dados brasileira (art. $2^{\circ}$, II). O presente artigo faz o percurso histórico-conceitual de como o direito à autodeterminação surge na jurisprudência alemã, abordando ainda os seus antecedentes, como o direito geral à liberdade de ação e o direito geral de personalidade. Entender sua evolução é tarefa essencial para bem compreender tanto o seu núcleo fundamental quanto seus limites e releituras. Ademais, a análise da jurisprudência do Tribunal Constitucional, no tocante à forma como terceiros lidam com dados e informações, pode fornecer esclarecimentos sobre características importantes da proteção de dados em geral. Assim, utiliza-se como metodologia a análise qualitativa da jurisprudência do Tribunal Constitucional, a fim de se compreender as origens e o desenvolvimento do conceito de autodeterminação informativa.

Palavras-chave: Autodeterminação informativa. Proteção de dados pessoais. Direito da personalidade. Tribunal Constitucional alemão.

\section{Abstract}

The right to informational self-determination represents one of the most well-known expressions in the data protection debates. The concept is relevant not only in Germany, but in several foreign regulations. For instance, it has been incorporated as one of the foundations of the Brazilian General Data Protection Law (art. 2, II). This paper outlines a qualitative analysis regarding the historical and conceptual path of the right to self-determination in the German Constitutional Court's case law. Understanding its evolution is an essential task to comprehend both its conceptual core, as well as its limitations and reinterpretations. Furthermore, it can provide important insights on key features regarding data protection law in general.

Keywords: The Right to Information Self-Determination. Data Protection. Personality Rights. German Constitutional Court.

\section{Introdução'}

Nos debates sobre proteção de dados pessoais, o direito à autodeterminação informativa representa uma das expressões mais renomadas. O conceito não fez apenas uma "carreira brilhante" (BULL, 2011, p. 25) na Alemanha, como também influenciou diversos ordenamentos estrangeiros, tendo sido inclusive incorporada como um dos fundamentos da Lei Geral de Proteção de Dados brasileira (art. $2^{\circ}$, II).

\footnotetext{
Doutora summa cum laude em Direito Privado pela Universidade Humboldt de Berlim. Mestre em Direito, Estado e Constituição pela Universidade de Brasília (UnB). Bacharel em Direito pela Universidade de Brasília (UnB). Professora Adjunta de Direito Civil da Universidade de Brasília (UnB) e do Instituto Brasiliense de Direito Público (IDP). Compõe o Conselho Diretor da Associação Luso-Alemã de Juristas (DLJV-Berlim) e do Instituto Brasileiro de Política e Direito do Consumidor (Brasilcon). Diretora do Centro de Direito, Internet e Sociedade do IDP (CEDIS). Foi uma das autoras do anteprojeto de lei de proteção de dados que resultou na Lei Geral de Proteção de Dados (Lei n. 13.709/2018). Brasília - DF - Brasil. E-mail: laura.schertel@unb.br.

O presente artigo tem como base o primeiro capítulo da tese de doutorado da autora, defendida na Universidade Humboldt de Berlim no ano de 2014, intitulada "Schutz gegen Informationsrisiken und Gewährleistung einer gehaltvollen Zustimmung: Eine Analyse der Rechtmäßigkeit der Datenverarbeitung im Privatrecht" (A proteção de dados pessoais no setor privado: riscos do tratamento de dados e a garantia de um consentimento substancial). A tese foi publicada em alemão pela editora DeGruyter, em 2015, com o mesmo título e ainda é inédita no Brasil.
} 
Embora o direito à autodeterminação informativa tenha sido reconhecido constitucionalmente, pela primeira vez, na sentença referente ao recenseamento da população, em 1983, seu desenvolvimento ocorreu ao longo de distintos julgados do Tribunal Constitucional da Alemanha. (BVerfGE 65, 1, Recenseamento).

Entender sua evolução é tarefa essencial para bem compreender tanto o seu núcleo fundamental quanto seus contornos e releituras. Ademais, a análise da jurisprudência do Tribunal Constitucional, no tocante à forma como terceiros lidam com dados e informações, pode fornecer esclarecimentos sobre características importantes da proteção de dados em geral.

Como se verá, o surgimento do direito à autodeterminação informativa está intimamente ligado à própria história da proteção da personalidade como direito fundamental, na medida em que o Tribunal Constitucional o desenvolveu como um desdobramento do direito ao livre desenvolvimento da personalidade. Nesse sentido, antes de discutir sobre a formação do direito à autodeterminação informativa, é importante explorar, com maior atenção, o seu alicerce: o direito geral de personalidade concebido pela jurisprudência constitucional alemã.

\section{Antecedentes do direito à autodeterminação informativa na jurisprudência constitucional alemã}

Um longo caminho teve de ser percorrido até o reconhecimento de um direito à autodeterminação informativa pela Corte Constitucional alemã em 1983. Um aspecto interessante dessa jornada é que ela se apoia na evolução da interpretação de um único artigo da Lei fundamental da Alemanha: o art. $2^{\circ}$, $\S^{\circ}$, que garante que todos têm direito ao livre desenvolvimento de sua personalidade. O presente tópico analisará a evolução jurisprudencial que antecedeu à formulação de um direito à autodeterminação informativa, em especial todo o caminho que levou à formulação de um direito geral de personalidade, sem o qual o direito à autodeterminação informativa não pode ser compreendido.

\subsection{A liberdade geral de ação (Die allgemeine Handlungsfreiheit)}

A lei fundamental alemã prevê em seu art. $2^{\circ}, \S 1^{\circ}$, o seguinte: "Todos têm o direito ao livre desenvolvimento de sua personalidade". O sentido dessa norma e sua aplicabilidade concreta foram, durante longo período, muito controversos, especialmente no que se refere à questão se ela deveria ser interpretada de forma mais ampla ou mais estrita.

Por exemplo, em sua decisão sobre o auxílio ao investimento (BVERFGE 4, 7 (15)), no ano de 1954, o Tribunal Constitucional não esclareceu se essa norma significaria uma "garantia abrangente da liberdade de ação" ou unicamente a representação de uma "proteção do mínimo de liberdade de ação humana, sem a qual o homem não é capaz de desenvolver sua essência como personalidade mental e moral". (KUBE, 2009, p. 90; JARASS, 1996, p. 89-90).

Três anos mais tarde, no ano de 1957, na sentença "Elfes" (BVerfGE 6, 32), o Tribunal Constitucional elucida essa questão, no entanto não a favor de um direito da personalidade geral, mas em prol da liberdade geral de ação. Parece, assim, que a história do art. $2^{\circ}, \S 1^{\circ}$, da LF, que trata do livre desenvolvimento da personalidade, começa com o seu reconhecimento como um direito de liberdade geral de ação e a negação de que ele pudesse ser a base de um direito geral da personalidade (JARASS, 1996, p. 90). Eis um resumo do litígio no caso:

O reclamante, W. Elfes, foi um político atuante nos âmbitos municipal e estadual em NordrheinWestfalen desde os anos 1930. Nos anos 1950, foi um dos líderes do partido político 'União dos Alemães', que combatia as políticas de reunificação (com a antiga República Democrática Alemã) e de defesa do governo federal. Tais teses críticas foram por ele diversas vezes defendidas, tanto dentro como fora da Alemanha. O reclamante teve seu requerimento de prorrogação da validade de seu passaporte denegada pela autoridade competente, que se valeu, em sua decisão administrativa, de um dispositivo da lei de passaportes que prescrevia a denegação do referido pedido toda vez que isso fosse necessário em face de uma ameaça à segurança ou ao interesse relevante da República 
Federal da Alemanha ou de um Estado-membro da federação. Após trilhar e esgotar a via jurisdicional administrativa, o reclamante ajuizou então sua Reclamação Constitucional contra a decisão (Urteil) de última instância do Tribunal Federal Administrativo.

O TCF julgou improcedente a reclamação, porque: $1^{\circ}$ ) negou que a área de proteção do Art. 11 GG que garante a livre circulação (porém no sentido de livre circulação e fixação de domicílio em território nacional) tivesse sido atingida, restando somente o Art. 2 I GG, o qual tutela subsidiariamente os direitos gerais da personalidade e a liberdade geral da ação, como parâmetro do controle; e $2^{\circ}$ ) considerou o dispositivo aplicado pelos tribunais administrativos como sendo parte da ordem constitucional, um dos limites legítimos, segundo o Art. 2 I GG, impostos à liberdade, no caso a princípio protegida, de sair do território nacional. (MARTINS, 2005, p. 190).

Em seu recurso ao Tribunal Constitucional, o reclamante se referiu, entre outros aspectos, ao seu direito à liberdade de locomoção e ao domicílio, de acordo com o art. 11, $\S 1^{\circ}$, da LF (GRIMM, 1997, p. 5; JARASS, 1996, p. 90).

Primeiramente, o Tribunal Constitucional analisou, em sua decisão, a aplicabilidade do art. $11, \S 1^{\circ}$, da LF ao caso concreto nos seguintes termos: "O art. 11, $\S 1^{\circ}$, LF garante a liberdade de locomoção e domicílio 'dentro de todo o território federal'. Estas palavras não denotam que deva ser concedido também um direito fundamental a sair livremente do território federal. [...] Não se falou da liberdade em se deixar o país. (BVerfGE 6, 32, Elfes)."

Em seguida, o Tribunal Constitucional examinou qual direito fundamental deveria ser aplicado ao caso. Quando se analisa o art. $2, \S 1^{\circ}$, levanta-se a questão deixada em aberto: este direito fundamental possui âmbito de proteção mais estrito ou mais amplo? O Tribunal parte do princípio de que a redação do artigo só possibilitaria a interpretação mais ampla, que supõe uma liberdade geral de ação, conforme a seguinte fundamentação:

[...] o dispositivo constitucional que estabelece o 'livre desenvolvimento da personalidade' não pode ser entendido apenas como base para um direito à personalidade, que constitui a essência do homem como ser moral, pois não seria compreensível que o desenvolvimento de sua personalidade poderia infringir a lei moral, os direitos de terceiros ou até mesmo a ordem constitucional de uma democracia liberal, conforme estabelece a parte final do dispositivo. São precisamente estas restrições impostas ao indivíduo como membro da comunidade que mostram que a Lei Fundamental em seu art. $2^{\circ}$, $\S 1^{\circ}$, compreende a liberdade de ação em sentido abrangente. (BVerfGE 6, 32, Elfes, tradução livre).

Por conseguinte, o Tribunal concluiu que a faculdade de deixar o país estaria incluída na liberdade geral de ação garantida pelo art. $2^{\circ}, \S 1^{\circ}$, da $L F$, e que a lei relativa aos passaportes deveria ser entendida como uma limitação, porém condizente com os termos da ordem constitucional. (BVerfGE 6, 32, Elfes). Por essas razões, o recurso interposto junto ao Tribunal Constitucional foi indeferido.

A contribuição do julgado supracitado consiste na formulação de que o direito fundamental ao livre desenvolvimento da personalidade é compreendido, na primeira fase da jurisprudência constitucional alemã, como base da liberdade geral de ação. Consequentemente, esse direito fundamental assume uma acepção protetiva ampla: deve proteger todo comportamento humano, não sendo resguardado por outros direitos fundamentais específicos. Assim, na interpretação do Tribunal Constitucional exposta no caso Elfes, nota-se que o art. $2^{\circ}, \S 1^{\circ}$, da LF não é a base para proteção da personalidade.

Teria sido possível outra solução para o caso se o Tribunal Constitucional tivesse se baseado em uma sentença anterior do Tribunal de Justiça Federal da Alemanha (BGH), a sentença Schachtbrief [Carta de Schacht], do ano de 1954 (GRIMM, 1997, p. 6). O cerne dessa decisão trata da publicação não autorizada de uma solicitação de retificação feita por um advogado, veiculada na coluna "Carta dos Leitores" de um jornal. Afastando-se do entendimento anterior exposto pelo Tribunal do Reich e ultrapassando a proteção aos direitos autorais, o Tribunal de Justiça Federal $(\mathrm{BGH})$ alemão estabelece um direito da personalidade geral, formulado a partir da combinação do art. $2^{\circ}, \S 1^{\circ}$, com o art. $1^{\circ}$ da LF, e qualifica a publicação como ilegal (KUBE, 2009, p. 89). O referido Tribunal reafirmou naquela ocasião o princípio segundo o qual cartas ou demais registros particulares não poderiam ser publicados, via de regra, sem o consentimento do autor 
e, quando fossem, apenas poderiam ser feitas na estrita forma autorizada por ele. (BGH [Tribunal Federal de Justiça/Causas Cíveis] 13, 34, Carta do Leitor).

Embora essa concepção do direito da personalidade geral não tenha sido empregada na sentença Elfes do Tribunal Constitucional alemão, as decisões seguintes do Tribunal revelam a convergência de seus entendimentos posteriores com a do Tribunal de Justiça Federal no que diz respeito à interpretação do art. $2^{\circ}, \S 1^{\circ}$, da LF. É dizer: a liberdade geral de ação não mais bastava para solucionar os complexos casos relacionados à personalidade (GRIMM, 1997, p. 7). Com esse desenvolvimento da jurisprudência, permitiu-se, posteriormente, que a liberdade de ação e o direito da personalidade fossem invocados como direitos autônomos a partir do art. $2^{\circ}, \S 1^{\circ}$, da LF, cada um com seu próprio âmbito de proteção (JARASS, 1989 , p. 857-858).

\subsection{O direito ao respeito à esfera privada (Das Recht auf Achtung der Privatsphäre)}

Na presente análise da jurisprudência sobre o livre desenvolvimento da personalidade, ganha relevo o momento em que a Corte constitucional reconhece que a norma do art. $2^{\circ}, \S 1^{\circ}$, da LF abriga não apenas o direito de liberdade geral de ação (caso Elfes), mas também o direito ao respeito à esfera privada. Isso se dá com as decisões do microcenso (BVerfGE 27, 1 (6)) e dos autos de divórcio (BVerfGE 27, 344 (352)), dos anos de 1969 e 1970, respectivamente, que serão apresentadas a seguir.

Para que essa evolução jurisprudencial pudesse ocorrer, foi preciso, em primeiro lugar, a percepção de que a liberdade geral de ação não representava um conceito de proteção suficiente contra ameaças da vida moderna à personalidade. Como a liberdade de ação protege exclusivamente o livre comportamento do indivíduo, esse direito é inadequado para proteção do indivíduo contra a ação de terceiros (GRIMM, 1997, p. 7). E isso ficou claro tanto no caso do microcenso como no caso dos autos do divórcio, uma vez que em ambos tratou-se de averiguar qual proteção contra ação de terceiros o direito fundamental albergado no art. $2^{\circ}, \S 1^{\circ}$, da LF conferia.

A decisão sobre o microcenso referia-se à lei para realização de um censo populacional, no qual múltiplas informações de caráter pessoal sobre os cidadãos deveriam ser levantadas, tais como: quantidade e nome das pessoas existentes na casa, sexo, idade, estado civil, número de filhos, participação ou não na vida profissional, viagens de férias e lazer, rendimentos financeiros etc.

Nesse contexto, todavia, o Tribunal Constitucional ocupou-se, sobretudo, em analisar o tema acerca das viagens de férias e de lazer: seria inconstitucional o levantamento de tais informações? Para examinar tal problemática, a Corte retoma o princípio mencionado no caso Elfes, isto é, a garantia do "âmbito inviolável do estilo de vida privado, que se subtrai à ação do Poder Público". (BVerfGE 27,1 (6)). Segundo o Tribunal, a Constituição concede à pessoa humana valor social e respeito, por conseguinte, é vedado ao Estado "registrar e catalogar um indivíduo acerca de aspectos envolvendo toda a sua personalidade, de forma coercitiva”. (BVerfGE 27,1 (6)).

Logo, o Tribunal concebe um "espaço interior" da personalidade que representa verdadeiro pressuposto do autodesenvolvimento da pessoa humana, sendo protegido contra intervenções:

\footnotetext{
Tal invasão no âmbito da personalidade por meio de um exame abrangente da situação pessoal de seus cidadãos é indeferida ao Estado também porque, no interesse do desenvolvimento livre e responsável da personalidade do indivíduo, deve ser deixado a ele um 'espaço interior', no qual 'tem a posse de si mesmo' e 'para o qual pode se retirar inabilitando o seu acesso pelo mundo que o envolve. Trata-se de espaço no qual ele é deixado em paz e goza do direito de ficar sozinho'. (BVerfGE 27,1 (6), tradução livre).
}

Após afirmar esse entendimento sobre o conteúdo do direito, o Tribunal avalia se a informação sobre as viagens de férias violaria esse espaço interior da personalidade. De forma bastante interessante, o Tribunal acaba por considerar que não haveria uma violação desse direito, por entender que a informação sobre as viagens de férias e lazer não atingiria a "esfera íntima" da pessoa, pois seriam informações do "mundo exterior", destituídas de um "caráter sigiloso". (BVerfGE 27, 1 (7)). Embora o Tribunal Constitucional tenha 
considerado a lei constitucional, originou-se, dessa decisão, um importante princípio para a fundamentação da proteção à esfera privada do indivíduo.

Um ano após essa decisão, o Tribunal Constitucional reafirmou, no caso referente aos autos do divórcio, a concepção do direito ao respeito da esfera privada, possibilitando, com isso, a formatação dessa esfera como um direito fundamental, amparado no art. $2^{\circ}, \S^{\circ}{ }^{\circ}$, da LF (ALBERS, 2005, p. 194). Nesse último caso, debateu-se se o envio dos autos de um processo de divórcio do investigado ao responsável por investigação no âmbito de um processo administrativo disciplinar representaria uma violação do direito ao respeito à vida privada. O Tribunal Superior Estadual de Hamm considerou constitucional o envio dos autos do divórcio, sendo interposto recurso junto ao Tribunal Constitucional contra essa decisão. Ao apreciar a demanda, a Corte Constitucional salientou duas ideias: a concepção do âmbito inviolável da vida privada e o imperativo do respeito à esfera íntima.

Nessa linha, o Tribunal argumentou que o conteúdo dos autos do processo de divórcio estaria adstrito à esfera íntima das pessoas nele envolvidas. Por essa razão, não seria possível ter acesso a tais informações sem o consentimento dessas pessoas:

Considerando seu conteúdo, os autos do processo de divórcio estão sujeitos ao sigilo, com fulcro no art. $2^{\circ}, \S 1^{\circ}$, combinado com o art. $1^{\circ}, \S 1^{\circ}$, LF. Ambos os cônjuges têm direito conjunto a esta proteção. $\mathrm{O}$ acesso por terceiros ao conteúdo dos autos [do processo de divórcio] só é regularmente possível, portanto, com base em uma declaração de anuência conferida por ambos. (BVerfGE 27, 344 (352)).

Destarte, o que se percebe é que o Tribunal Constitucional confirmou que teria ocorrido uma intervenção ilegítima no direito da personalidade dos cônjuges, anulando, consequentemente, a sentença do Tribunal Superior Estadual. Com essa decisão, a Corte consolidou a garantia constitucional de proteção da esfera privada (GRIMM, 1997, p. 7).

Por sua vez, a decisão referente à fita fonográfica (BVerfGE 34, 238 (238)), do ano de 1973, representa mais uma consolidação da jurisprudência do Tribunal Constitucional referente à proteção da esfera privada, todavia ela possibilita, simultaneamente, a adaptação e o desenvolvimento dessa concepção. Eis o resumo do caso:

\footnotetext{
Um casal vendeu ao reclamante um imóvel, segundo eles, por 495.000 marcos alemães, no dia 11 de maio de 1970. A escritura foi passada, porém, no valor de 425.000 marcos. 70.000 marcos foram pagos à parte em moeda corrente. $O$ casal assinou um recibo preparado pelo reclamante de 'empréstimo' da quantia, o qual deveria ser destruído quando do registro da escritura, o que foi de fato feito na ocasião na presença do casal que alienou o imóvel. Porém, o reclamante cobrou algum tempo depois do referido casal o pagamento do suposto empréstimo apresentando um segundo recibo de 70.000 marcos alemães. Em 14 de dezembro do mesmo ano, o casal registrou um boletim de ocorrência policial por estelionato e falsificação de documento. O casal gravou, no entanto, uma fita fonográfica (Tonband) de uma conversa tida em agosto de 1970 sobre o acordo verbal realizado entre eles, sem o conhecimento e, portanto, consentimento do reclamante. O juízo de primeira instância de Osnabrück atendeu ao pedido do Ministério Público local no sentido de utilizar a gravação como prova da acusação. O Tribunal Estadual de Osnabrück denegou, em suma, a reclamação ordinária (Beschwerde) 228. Contra essa decisão (Beschluss) do Tribunal Estadual de Osnabrück foi ajuizada a Reclamação Constitucional, que foi julgada. (MARTINS, 2005, p. 195).
}

O objeto do referido caso dizia respeito à seguinte questão: seria admissível utilizar uma gravação do investigado obtida secretamente, em fita fonográfica particular, no processo de sonegação fiscal movido contra ele? O Tribunal Regional de Justiça de Osnabrück considerou lícita a utilização da fita, com a fundamentação de que a pretensão do Estado ao imposto sobre a renda imobiliária predominaria sobre o direito fundamental do indivíduo ao livre desenvolvimento de sua personalidade.

O Tribunal Constitucional anulou a decisão do Tribunal Regional alegando ter ocorrido frontal violação ao art. $2^{\circ}, \S 1^{\circ}$, combinado com o art. $1^{\circ}, \S 1^{\circ}$, da LF. A decisão abarca dois níveis de argumentação. Em primeiro lugar, a Corte constatou que a Lei Fundamental alemã concede a todo indivíduo um "âmbito inviolável da vida privada, que escapa à atuação do poder público". (BVerfGE 34, 238 (245)). Nem mesmo 
um interesse preponderante geral poderia afetar esse âmbito, uma vez que a Lei Fundamental prevê a dignidade humana como preceito inviolável. (BVerfGE 34, 238 (245)). Ocorre, no entanto, que, segundo o Tribunal Constitucional, no caso analisado, a gravação dizia respeito a uma conversa comercial e, portanto, não se enquadraria no âmbito inviolável da vida privada. (BVerfGE 34, 238 (248)).

Em razão disso, é possível, na visão do Tribunal, continuar a análise sobre a viabilidade de utilização da fita gravada na investigação: "Como não se trata de uma intervenção do poder público no âmbito absolutamente protegido da personalidade, a utilização da gravação seria permitida se fosse justificada por um interesse público preponderante. Não é o caso." (BVerfGE 34, 238 (248)). Entendeu, assim, o Tribunal Constitucional que não haveria no caso um interesse público que superasse a garantia da proteção à gravação nesse caso de suspeita de sonegação fiscal. (BVerfGE 34, 238 (249)).

Por conseguinte, o Tribunal constitucional decidiu que o recurso interposto estaria fundamentado, formulando-o como parte da dimensão de proteção da esfera privada e do direito à palavra falada, tendo "cada pessoa o direito de determinar quem pode gravar sua voz, bem como se e diante de quem pode ela será reproduzida". (BVerfGE 34, 238 (238)).

Como demonstrado, as decisões nos casos microcenso e os autos do processo de divórcio são basilares para o surgimento do direito ao respeito da esfera privada, que se distingue da liberdade geral de ação (ALBERS, 2005, p. 194). O direito ao respeito à esfera privada fornece importantes contribuições à proteção dos direitos fundamentais. Diferentemente da liberdade geral de ação, ele não protege o livre comportamento da própria pessoa, mas protege a pessoa contra ações de outros (GRIMM, 1997, p. 7). Sua construção dogmática fundamental consiste em relacionar dados e informações com a pessoa, a fim de definir efeitos jurídicos (ALBERS, 2005, p. 206).

Cria-se uma esfera de isolamento que protege tanto uma área de refúgio, na qual a pessoa é deixada em paz, quanto a expectativa de sigilo. Como a esfera privada designa um âmbito individual, o direito ao respeito da esfera privada protege, dentre outras, a confiança na manutenção do sigilo das informações pessoais, a integridade psíquica e a confiabilidade das relações conjugais (ALBERS, 2005, p. 207).

Essa concepção desenvolvida pelo Tribunal Constitucional Federal tem grande êxito por se apropriar da clássica dogmática na qual os direitos fundamentais são primordialmente vistos como direito de defesa (ALBERS, 2005, p. 207). Isso implica que, para se investigar a existência de uma violação à esfera privada, é preciso examinar se a informação coletada ou processada pode ser atribuída a essa esfera privada.

Esse exame pode ser visto, sobretudo, nas decisões referentes aos casos do microcenso e dos autos de divórcio, nos quais o Tribunal Constitucional aplica o mesmo método: enquanto no primeiro não foi atestado nenhum prejuízo à personalidade, uma vez que as informações em questão sobre as viagens de férias e lazer não são atribuídas à esfera íntima (BVerfGE 27, 1 (7)), o Tribunal considera inconstitucional o envio dos autos do divórcio por avaliar como íntimas as informações conjugais. (BVerfGE 27, 344 (352)).

Apesar dos resultados mencionados, o direito ao respeito à esfera privada sofreu muitas críticas, que viriam beneficiar, posteriormente, a formulação de um direito à autodeterminação informativa. Primeiramente, menciona-se frequentemente que o conceito utilizado pela Corte constitucional alemã basear-se-ia na teoria das esferas de Heinrich Hubmann (ALBERS, 2005, p. 208). Segundo essa teoria, a personalidade está marcada pela representação dos círculos espaciais concêntricos, os quais merecem proteção diferenciada (HUBMANN, 1967, p. 269; BASTON-VOGT, 1997, p. 182). Assim, haveria a esfera íntima, que seria intocável, a esfera privada, que estaria protegida, mas que poderia ser igualmente restringida, e a esfera individual e social, que não estaria protegida (HUBMANN, 1967, p. 269).

Embora a teoria das esferas possa ter influenciado a jurisprudência constitucional, a concepção do Tribunal Constitucional, em comparação à rígida fórmula das esferas, é muito mais complexa e de orientação mais funcional (ALBERS, 2005, p. 200). O problema da delimitação que surge na concepção da esfera privada não reside em seu suposto embasamento na teoria das esferas, mas sim na questão dogmática subjacente a todo projeto de proteção relacionado a âmbitos de proteção, qual seja, qual conteúdo deve ser protegido (ALBERS, 2005, p. 210). 
O segundo ponto levantado em relação ao direito ao respeito à esfera privada refere-se à relatividade desta, uma vez que os desejos de privacidade podem diferir muito fortemente de pessoa para pessoa (MALLMANN, 1995, p. 26). Assim, âmbitos de proteção não poderiam ser designados rigidamente de esfera privada ou íntima, "pois os espaços vitais, nos quais o indivíduo se refugia para descansar das exigências sociais, preparar um comportamento social e fazer tudo o que não pode ser trazido para a sociedade e representado diante dela, são relativos". (SCHLINK, 1986, p. 233; 241).

À concepção da esfera privada ainda é feita outra crítica, estritamente relacionada ao princípio da relatividade da esfera privada, qual seja, a noção do contexto de aplicação. Ela se refere à ideia de que "a sensibilidade e o conteúdo de significado de informações dependem do respectivo contexto de aplicação". (MALLMANN, 1995, p. 26). Assim, a finalidade da coleta (SCHLINK, 1982, p. 192) e o destinatário da informação são mais decisivos para a avaliação da constitucionalidade do processamento de dados do que a classificação dos dados em privados ou íntimos (ALBERS, 2005, p. 212).

Os princípios da relatividade da esfera privada e do contexto de aplicação foram posteriormente retomados pelo Tribunal Constitucional e são imprescindíveis para a gênese do direito à autodeterminação informativa, como veremos adiante (ALBERS, 2005, p. 213).

\subsection{O direito geral de personalidade (Das allgemeine Persönlichkeitsrecht)}

Após a análise do desenvolvimento do direito ao respeito à esfera privada, debateremos, neste tópico, as origens do direito geral da personalidade na jurisprudência constitucional alemã.

A principal característica do direito geral de personalidade é o fato de ter se originado na prática jurisprudencial, o que acabou por marcar a evolução desse instituto de forma não sistemática e específica a cada caso (GRIMM, 1997, p. 3-4). Ele cumpre a função de fechamento de lacuna e tem o objetivo de proteger a personalidade contra novas e inesperadas ameaças tecnológicas. Assim, o caráter "aberto e a dinâmica" do direito geral de personalidade requerem uma investigação dogmática que contemple seu desenvolvimento de forma sistemática, a fim de que possa ser apreendida a ideia fundamental por trás dos diferentes casos (GRIMM, 1997, p. 3-4).

A concepção de proteção da esfera privada que se consolidou na jurisprudência do Tribunal Constitucional nas décadas de 60 e 70 logo revelou os seus limites. Como muitos casos representavam um desafio ao direito da proteção da esfera privada, o Tribunal Constitucional teve que dar um passo adiante e reconhecer o direito geral da personalidade como garantia constitucional prevista na LF.

O primeiro avanço é a sentença no caso "Soraya", do ano de 1973, e diz respeito à publicação de uma entrevista fictícia da esposa divorciada do xá do Irã, a princesa Soraya. (BVerfGE 34, 269). A editora do jornal "Die Welt" publicara a entrevista fictícia, tendo sido condenada pelo Tribunal Regional de Justiça de Mannheim ao pagamento de 15.000 DM [marcos alemães] por danos morais, sob o fundamento de ter violado o direito da personalidade da princesa Soraya. O Tribunal Federal de Justiça (BGH) reconheceu a decisão, inclusive considerando legítima a condenação pecuniária, com o argumento de que, no caso de graves violações à personalidade, poderia ser exigida uma reparação em dinheiro quando não fosse possível reestabelecer por outros meios a situação anterior à intervenção. (BVerfGE 34, 269 (277)).

Especialmente importante nesse caso são as discussões a respeito da base legal para aplicação dos danos morais, isto é, se poderiam ser derivados do Código Civil alemão, embora não previstos expressamente, bem como o debate sobre as competências do Tribunal Federal de Justiça e se ele teria extrapolado sua competência ao apresentar tal interpretação.

O Tribunal Constitucional alemão confirmou a decisão do Tribunal Federal de Justiça, tanto no tocante ao seu método quanto a seu resultado. Ele considerou que a aplicação criativa do Direito é reconhecida na Lei Fundamental e a interpretação dos tribunais cíveis seria, destarte, constitucional, pois esta "não teria feito valer nenhuma vontade jurídico-política própria, mas apenas desenvolvido de forma continuada as ideias fundamentais do ordenamento jurídico já cunhadas na LF”. (BVerfGE 34, 269 (292)). 
A importância da sentença reside, primeiramente, no fato de que o direito da personalidade geral é reconhecido como garantia constitucional, que está em pé de igualdade com a liberdade de imprensa (art. $5^{\circ}, \S 1^{\circ}$, frase 2, LF), e deve ser ponderada com esta (ALBERS, 2005, p. 217). Em segundo lugar, a decisão é relevante na história conceitual aqui analisada, porque o Tribunal Constitucional acaba por aplicar o conceito de autodeterminação ainda que, expressamente, mencione a existência de uma esfera privada (ALBERS, 2005, p. 218).

A segunda sentença na sequência de casos do direito da personalidade geral é a decisão no caso "Lebach", que possibilita um aprofundamento da discussão sobre o bem protegido por esse direito (BVerfGE $35,202)$. Trata-se de um filme documentário sobre o assassinato do soldado Lebach que a emissora de televisão ZDF desejava transmitir. Um dos criminosos, que havia sido solto na mesma época, requereu, por meio de recurso ao Tribunal Constitucional, que a emissora deixasse de exibir o documentário por colocar em risco suas chances de ressocialização.

O Tribunal Constitucional considerou justificado o recurso com a seguinte argumentação:

Para a reportagem atual sobre crimes graves, o interesse do público em geral pela informação merece primazia frente à proteção da personalidade do autor do crime. [...] Contudo, a proteção constitucional da personalidade não admite que a televisão se ocupe, para além da reportagem atual, por exemplo, na forma de um filme documentário, da pessoa de um criminoso e de sua esfera privada de modo temporalmente ilimitado. Em todo caso, uma reportagem posterior é inadmissível quando se prestar a produzir, frente à informação atual, um prejuízo consideravelmente novo ou adicional à pessoa do autor do crime, especialmente quando coloca em risco sua reinserção na sociedade (ressocialização). (BVerfGE 35, 202 (203), Lebach, tradução livre).

Tal decisão opera uma mudança de perspectiva, ao sair da proteção da esfera privada para um direito da personalidade geral e abstrato. Apenas assim pode ser compreendido o resultado da sentença, uma vez que o caso não atinge nem temas privados nem o desenvolvimento da pessoa no âmbito de sua esfera privada. Trata-se, exclusivamente, do desenvolvimento da personalidade no âmbito da sociedade.

Essa mudança paradigmática foi alicerçada pela decisão no caso "Eppler", do ano de 1980. (BVerfGE 54, 148). O recurso ao Tribunal Constitucional foi impetrado por Eppler, o então presidente da Associação Estadual de Baden-Württemberg do Partido Social-Democrata (SPD), contra a Associação Estadual de Baden-Württemberg do Partido da União Democrata-Cristã (CDU) com o argumento de que o conteúdo de um discurso-modelo do CDU teria lesado sua personalidade na campanha eleitoral para o parlamento estadual.

Ele alegou que the teriam sido atribuídas palavras que não havia dito acerca da capacidade de resistência da economia alemã. O Tribunal Constitucional inadmitiu o recurso, sob o fundamento de que não foi comprovado perante os juízos cíveis que o reclamante não teria proferido as palavras controversas.

A importância da decisão reside no fato de que o Tribunal Constitucional aproveitou a oportunidade para expor uma explicação minuciosa da concepção do direito geral da personalidade. Assim, é explicitamente estabelecido, pela primeira vez, que esse direito da personalidade representa um "direito de liberdade indefinido", que complementaria os direitos de liberdade específicos. Fica, ademais, reconhecido que sua tarefa é

proteger, nos termos do princípio constitucional da 'dignidade da pessoa humana' (art. $1^{\circ}, \S 1^{\circ}, \mathrm{LF}$ ), a esfera de vida pessoal mais íntima e a conservação de suas condições básicas que não podem ser captadas de forma conclusiva pelas tradicionais garantias concretas de liberdade. (BVerfGE 54, 148 (153) Eppler).

Importante, outrossim, a ideia fundamental de que os desenvolvimentos modernos poderiam acarretar novos riscos para o indivíduo, o que representaria um grande desafio para a proteção da personalidade na atualidade. Logo, o direito geral de personalidade serviria para conceder proteção por meio de sua formulação abstrata contra riscos ainda desconhecidos e imprevisíveis. Segundo o Tribunal Constitucional, não é possível circunscrever de forma conclusiva o conteúdo desse direito; de fato, diversas manifestações foram desenvolvidas pela jurisprudência: a esfera privada e a íntima, a honra pessoal, o direito de dispor 
sobre a apresentação da própria pessoa bem como o direito à própria imagem e à palavra falada. (BVerfGE 54, 148 (154), Eppler).

A sentença no caso Eppler representa uma virada na jurisprudência alemã a respeito da proteção da personalidade. A partir dela, o direito da personalidade é definitivamente ancorado no Direito Constitucional e não mais é compreendido apenas como parte do ordenamento jurídico-civil (GRIMM, 1997, p. 13). É de se notar, também, que o direito da personalidade não mais é visto como barreira a outros direitos, e sim como direito fundamental autônomo que se distingue da liberdade geral de ação.

Ademais, pelo fato de a autodeterminação desempenhar um papel decisivo nesse novo direito, a decisão no caso Eppler designa uma transformação de concepção das ideias fundamentais da proteção da personalidade. Assim, o direito da personalidade geral significa, principalmente, o direito da pessoa em decidir por si mesma como ela deseja se apresentar em público (GRIMM, 1997, p. 13-14). Nos termos do Tribunal Constitucional, o direito geral de personalidade baseia-se na "ideia da autodeterminação", o que significa que:

[O] indivíduo deve basicamente [...] poder decidir por si mesmo como ele deseja se apresentar frente a terceiros ou ao público, se e em que medida terceiros podem dispor de sua personalidade; disto também faz especialmente parte a decisão de como ele quer se colocar em evidência com suas próprias palavras. (BVerfGE 54, 148 (155), Eppler).

Outra decisão que desempenhou uma função importante no âmbito da jurisprudência referente ao direito geral de personalidade foi o caso "Böll". Nele se discutiu se um comentário veiculado na televisão, segundo o qual Heinrich Böll é chamado de terrorista, estaria protegido pelo direito à liberdade de expressão e se houve lesão à honra do escritor. (BVerfGE 54, 208, Böll).

O Tribunal Constitucional observa que o direito fundamental à liberdade de expressão não encobriria a citação incorreta, constatando que seria inconstitucional publicar uma declaração do criticado como citação "sem identificar que se trata de uma interpretação do crítico". (BVerfGE 54, 208 (221), Böll). Com a sentença no caso Böll, a proteção da honra, como expressão do direito da personalidade geral, adquire caráter de direito fundamental. Essa decisão vai oferecer, posteriormente, a base para o desenvolvimento da pretensão ao direito de resposta. (BVerfGE 63, 131, Direito de resposta).

Resumindo, pode-se dizer que dessa série de casos resulta uma nova abordagem em termos de direitos fundamentais, consubstanciado no direito geral de personalidade. Seu surgimento significa uma tentativa de superar os déficits e limitações da concepção da esfera privada e, consequentemente, criar para o indivíduo uma proteção ampliada na sociedade moderna. As propriedades do direito da personalidade geral podem ser resumidas no seguinte tripé: proteção abrangente, conceito de autodeterminação e abstração.

O direito geral de personalidade representa uma ampliação da proteção perante a concepção da esfera privada ao abranger, agora, não somente a estreita esfera privada, mas toda a personalidade. Isso é perceptível, sobretudo, nos casos Böll e Eppler, uma vez que se trata, em especial, de proteção da honra e da atribuição de supostas declarações públicas. Evidentemente, nenhuma das duas tem relação com a esfera íntima ou privada; trata-se, exclusivamente, da personalidade dos interessados, especialmente da apresentação da pessoa em público.

No centro dessa abordagem abrangente está localizada a ideia da autodeterminação, segundo a qual o próprio indivíduo deve decidir como deseja se apresentar em público. Esse desenvolvimento pode ser remetido, principalmente, à crítica sobre a concepção da esfera privada. As abordagens da relatividade da esfera privada e do contexto de uso de informações como fonte de risco, em especial, levaram a conceber o poder de decisão do indivíduo como bem a ser tutelado juridicamente, em vez de demarcar um âmbito de proteção consubstanciado na esfera privada (TRUTE, 2003, p. 164).

Com esse ponto de partida, o direito geral de personalidade passa ser formulado em um nível abstrato, de modo que ele possa oferecer proteção abrangente, tendo como ponto fulcral o conceito de autodeterminação. Dessa forma, na jurisprudência de direitos fundamentais, esse direito é apresentado como direito de liberdade indistinto, que complementa os direitos de liberdade específicos. 
Em relação a essa abstração, seu conteúdo não pode ser definido de forma conclusiva; existe somente uma definição específica na análise do caso concreto. Com isso, a função mais importante do direito da personalidade geral consiste em proteger o indivíduo contra futuras ameaças, que sempre podem voltar a surgir no cotidiano contemporâneo.

\section{0 direito à autodeterminação informativa (Das Recht auf informationelle Selbstbestimmung)}

Com a consolidação do direito geral da personalidade, o Tribunal Constitucional preparou o caminho para futuros desdobramentos. Afinal, sempre que surgirem novos conflitos e uma necessidade de proteção da personalidade ainda não contemplada pelo ordenamento jurídico, o caráter abstrato do direito da personalidade geral possibilita aplicar novas formas, a fim de garantir proteção suficiente para o indivíduo. Nesse contexto é que se compreende a origem do direito da autodeterminação informativa, que será contemplado nesse tópico.

\subsection{Origem do direito à autodeterminação informativa na doutrina alemã e na jurisprudência da Corte constitucional alemã: fundamentos e estrutura conceitual}

A sentença referente ao recenseamento da população, que será analisada abaixo, marca o surgimento do direito à autodeterminação informativa na jurisprudência do Tribunal Constitucional (BVerfGE 65, 1, Recenseamento). Contudo esse desenvolvimento foi marcado fortemente pelo debate dogmático da proteção de dados, no qual foi formulado, pela primeira vez, o conceito de autodeterminação informativa. Esse conceito surge no parecer redigido por Steinmüller et al. (1971, p. 88; 93) por incumbência do Ministério do Interior da Alemanha, ${ }^{2}$ sendo empregado em obras posteriores ${ }^{3}$ sobre o direito de proteção de dados nos anos de $1970 .^{4}$

Os autores do parecer pleiteiam por substituir a "inútil esfera privada" por uma nova abordagem capaz de fundamentar uma proteção de direito fundamental orientada para a informação. ${ }^{5}$ Conforme o parecer, do art. $2^{\circ}, \S 1^{\circ}$, da LF, resulta um direito de autodeterminação do cidadão, segundo o qual ele pode decidir "quais informações individuais ele fornece a quem e sob quais circunstâncias". 6

O direito de autodeterminação informativa aparece logo depois como critério para as fases do processamento da informação. ${ }^{7}$ Segundo os autores, é preciso se atentar ao risco resultante do processamento automatizado de dados (STEINMÜLLER et al., 1971, p. 88).

$\mathrm{Na}$ sentença referente ao recenseamento da população, o Tribunal Constitucional retoma tanto a abordagem da autodeterminação quanto a noção da limitação do comportamento por meio do processamento não transparente dos dados, a fim de conceber a partir do art. $2^{\circ}, \S 1^{\circ}$ combinado com o art. $1^{\circ}, \S 1^{\circ}$, LF (dignidade da pessoa humana), o direito fundamental à autodeterminação informativa. (BVerfGE 65,1, Recenseamento). Estes dois elementos marcam a dogmática deste direito até hoje, embora esta vinculação seja o objeto de forte crítica no Direito. ${ }^{8}$

Steinmüller et al.. Grundfragen des Datenschutzes, Gutachten im Auftrag des Bundesministeriums des Innern. BTdrucks VI/3826, anexo 1, 1971p. 88,93 . O ponto de partida do parecer é uma questão político-jurídica, mais precisamente, como deveria ser configurada uma futura lei de proteção de dados. Ao parecer subjaz a ideia de que a proteção de dados é o reverso do processamento de dados; assim, o conhecimento das possibilidades do processamento de dados foi visto como requisito para a legislação sobre proteção de dados (p. 34). Isso explica por que em muitos trechos o parecer se ocupa de termos técnicos e apresenta as fases do processamento de dados como ponto central (p. 57 ss.).

3 Mallmann (1995, p. 27 ss.); Adalbert (1979, p. 55); Benda, (1974, p. 34).

4 Sobre raízes bibliográficas do direito de autodeterminação informativa, cf.: Bull (2011, p. 23 ss.); Albers (2005, p. 115 ss., 213 ss.; Trute (2003, nota 27).

5 "A nova abordagem parte do fenômeno da informação e de seu processamento, ou seja, de um processo de fato; ele parte, assim, de uma realidade (simultaneamente social e 'técnica')". (STEINMÜLLER et al., 1971, p. 88; 93).

6“O processamento de informações individuais pela administração deve ser avaliado pelo fato se e o quanto ele lesa o direito da autodeterminação e, com isso, o direito ao livre desenvolvimento da personalidade". (STEINMÜLLER et al., 1971, p. 88).

"Critério, sob o qual deve ser avaliado o processamento público de informações, assim resulta do ponto 2 acima, é o direito de autodeterminação informativa sobre a própria formação da pessoa ou do grupo (modelo pessoal)”. (STEINMÜLLER et al., 1971, p. 93).

$8 \quad$ Cf. a respeito: Trute (2003, p. 163 ss.); Bull (2011, p. 31). 
Nesta decisão, tratou-se da discussão sobre a constitucionalidade da lei de 25 de março de 1982 , referente ao recenseamento da população, das profissões, das residências e dos locais de trabalho. O ponto de partida do acórdão é o processamento eletrônico de dados que, em virtude do moderno desenvolvimento tecnológico, possibilitou o processamento ilimitado, o armazenamento e a transmissão de dados pessoais em proporções até então desconhecidas.

De acordo com o Tribunal, as novas condições tecnológicas e sociais requerem o desenvolvimento continuado da interpretação dos direitos fundamentais para garantir a proteção do indivíduo na sociedade da informação. (BVerfGE 65,1 (42), Recenseamento).

Diferentemente da decisão a respeito do microcenso, fica nítido na sentença do recenseamento que a fórmula da esfera privada não representa uma concepção adequada para a solução do caso. Afinal, não mais importava se as informações coletadas dos cidadãos eram íntimas, privadas ou públicas; tratava-se, antes, dos riscos para a personalidade que poderiam surgir do processamento eletrônico de dados.

Assim, afirma o Tribunal que o processamento automatizado dos dados ameaçaria o poder do indivíduo de decidir por si mesmo se e como ele desejaria fornecer a terceiros os seus dados pessoais, considerando que o processamento de dados possibilitaria a elaboração de um "perfil completo da personalidade" por meio de "sistemas automatizados integrados sem que o interessado pudesse controlar de forma suficiente sua correção e utilização".

Tal utilização ampliaria a influência do Estado sobre o comportamento do indivíduo, que não mais seria capaz de tomar decisões livres em virtude "da pressão psíquica de participação pública". Uma sociedade, "na qual os cidadãos não mais são capazes de saber quem sabe o que sobre eles, quando e em que situação", seria contrária ao direito à autodeterminação informativa, algo prejudicial tanto para a personalidade quanto para o bem comum de uma sociedade democrática. (BVerfGE 65,1 (42), Recenseamento).

Destarte, o Tribunal Constitucional constata que do art. $2^{\circ}, \S^{\circ}$ (livre desenvolvimento da personalidade), combinado com o art. $1^{\circ}, \S 1^{\circ}$ (dignidade humana), da LF, resultaria um direito fundamental à autodeterminação informativa que garantiria "o poder do indivíduo em determinar sobre a coleta e utilização de seus dados pessoais". (BVerfGE 65,1 (43), Recenseamento). O Tribunal reforça que o direito fundamental não seria ilimitado, pois as informações pessoais denotariam um "retrato da realidade social" e, portanto, não poderiam ser atribuídas somente ao indivíduo.

Todavia esses limites somente seriam justificados em nome de um interesse geral preponderante. Ademais, eles teriam que ter uma base legal para cumprir tanto o imperativo da clareza das normas quanto o princípio da proporcionalidade. Por fim, teriam que ser tomadas providências de cunho organizacional para diminuir os riscos à personalidade do cidadão. (BVerfGE 65,1 (44), Recenseamento).

Decisivo para a concepção do direito à autodeterminação informativa é o princípio segundo o qual não mais existiriam dados insignificantes nas circunstâncias modernas do processamento automatizado de dados. O risco do processamento de dados residiria mais na finalidade do processamento e nas possibilidades de processamento do que no tipo dos dados tratados.

A fim de prestar proteção contra o risco decorrente do moderno processamento de dados, o Tribunal formula que todos os dados pessoais estariam abrangidos no âmbito de proteção do direito à autodeterminação informativa e que somente o próprio interessado poderia decidir sobre sua coleta, processamento e transmissão. (BVerfGE 65,1 (45), Recenseamento).

Isso significa que, na jurisprudência do Tribunal Constitucional, a mudança definitiva da concepção da esfera privada para o direito à autodeterminação informativa, na qual a atribuição de dados a uma esfera íntima não tem mais nenhum papel significativo. O Tribunal Constitucional alemão estendeu a proteção frente à coleta, armazenamento, utilização e transmissão aos dados pessoais em vez de limitá-la a uma esfera privada que protegeria somente informações íntimas (GRIMM, 1997, p. 15). Dessa forma, o Tribunal formula um princípio constitucional, já encontrado desde os anos de 1970 no direito à proteção de dados 
infraconstitucional, no qual o caráter pessoal de um dado era o fator decisivo de proteção, ${ }^{9}$ e não o fato de se tratar de dado íntimo ou privado.

O Tribunal Constitucional diferencia dados pessoais, que são individualizados, de dados anônimos, que são processados para fins estatísticos, colocando exigências distintas. Como, na maioria das vezes, não é possível limitar nas estatísticas a finalidade e as possibilidades de utilização, teriam que ser tomadas providências especiais, tais como a anonimização de dados e o sigilo.

O Tribunal destaca que, em censos populacionais, existe o risco de que o cidadão possa "se converter em mero objeto de informação" se o legislador não tomar as medidas adequadas para garantia de seus direitos. (BVerfGE 65,1 (48 ss.), Recenseamento).

Especialmente problemática para o direito à autodeterminação informativa seria, segundo o órgão jurisdicional, a transmissão de dados pessoais, ou seja, daqueles dados que não foram anonimizados. (BVerfGE 65,1 (51), Recenseamento). Assim constata o Tribunal Constitucional que, embora o programa de coleta de dados da lei de recenseamento de 1983 não conduza, no geral, à catalogação da pessoa, ele violaria, com suas regras de transmissão, a Lei Fundamental.

Assim, o Tribunal considerou o recurso como parcialmente fundamentado, anulando as regras de transmissão, com exceção da transmissão de dados anonimizados para fins científicos. (BVerfGE 65,1 (63 ss.), Recenseamento). A partir da argumentação do Tribunal, é patente que ele reúne diversos fundamentos para elaborar a formulação do direito à autodeterminação informativa, quais sejam: o direito geral de personalidade, a fórmula da autodeterminação e a tutela do dado pessoal de forma abrangente, independente da sua natureza íntima ou privada (TRUTE, 2003, p. 163; ALBERS, 1996, p. 113; 117 ss.).

Esse caminho em direção a uma abstração mais forte e a uma ideia abrangente de autodeterminação, já tomado com o direito da personalidade geral do Tribunal Constitucional, é consumado na sentença referente ao recenseamento da população, e também pode ser remetido à crítica que fora feita à relatividade da esfera privada e dos nexos de aplicação como base de risco.

Em resumo, de acordo com a jurisprudência do Tribunal Constitucional, o direito da autodeterminação informativa se baseia principalmente em três propriedades. Primeiramente, o poder de decisão é formulado como o âmbito de proteção do direito, de tal modo que o indivíduo pode decidir, ele próprio, sobre a coleta e utilização de informações de cunho pessoal (ALBERS, 2005, p. 235).

Daí resulta a segunda propriedade, qual seja, a de que o direito fundamental à autodeterminação informativa não abrange um teor de proteção fixo e definido, desviando-se, assim, do modelo de esfera privada de atribuição de dados a uma esfera íntima. Em terceiro lugar, a referência pessoal do dado atua decisivamente sobre o teor da proteção na medida em que cada registro que se revela como pessoal é merecedor de proteção.

Em princípio, pode-se observar que o direito à autodeterminação informativa se encontra em uma relação de continuidade com a concepção do direito da personalidade geral. É certo que o Tribunal Constitucional alemão teve que desenvolver um novo conceito na sentença referente ao recenseamento, a fim de proteger o indivíduo contra o processamento automatizado de dados, todavia logrou formular o novo direito fundamental como uma expressão do direito da personalidade geral, ou seja, dentro do já existente quadro da proteção da personalidade.

Disso decorre que a decisão referente ao recenseamento contribuiu não apenas para fundamentar o direito à autodeterminação informativa, mas também para consolidar o direito geral da personalidade como um conceito efetivo, flexível e de grande aplicação prática.

A importância do direito à autodeterminação informativa reside no fato de que a sua fórmula de proteção abstrata oferece grande flexibilidade como poder de decisão (ALBERS, 2005, p. 235). Como não

Sobre a influência da moderna concepção procedimental da proteção de dados no Direito comum sobre a sentença referente ao recenseamento, v. Mückenberger (1984, p. 1, 16 ss.). 
designa um conteúdo de garantia fixo, esse direito pode ser aplicado em múltiplos casos concernentes à coleta, processamento ou transmissão de dados ou informações pessoais.

De fato, desde a sentença relativa ao recenseamento da população, o direito à autodeterminação informativa foi usado como base para inúmeras decisões, como, por exemplo, a discussão sobre retenção de dados, o consentimento em contratos de seguro e a requisição de informações em contratos de aluguel, entre tantas outras. Simultaneamente, a concepção da autodeterminação informativa possibilita uma ampliação da proteção, uma vez que a proteção não mais é limitada aos dados da esfera íntima (ALBERS, 2005, p. 236).

Essa análise revela como o direito fundamental da proteção de dados se desenvolveu: ele se distanciou de uma proteção relacionada a um âmbito fixo de proteção (esfera íntima ou privada), transferindo sua base a um poder de decisão e a instrumentos procedimentais. Logo, ele é o resultado da superação da proteção da esfera privada, sendo marcado por um processo de abstração do seu âmbito de proteção (GRIMM, 1997, p. 13; ALBERS, 2005, p. 232).

\subsection{Deveres de proteção e eficácia horizontal}

$\mathrm{Na}$ sua origem, pouco se falava na aplicação do direito à autodeterminação informativa nas relações privadas, uma vez que se destacavam, nesse período, as ameaças do processamento de informação advindas do Estado. Contudo logo se percebeu que uma das suas principais aplicações seria na relação entre indivíduos e entes privados, em razão do crescente poder de processamento de dados pelas empresas.

Nesse sentido, destacam-se duas decisões do Tribunal Constitucional alemão sobre os efeitos nas relações privadas do direito à autodeterminação informativa.

O primeiro caso, do ano de 1991, tratou da questão a respeito da obrigação de uma pessoa interditada revelar a sua interdição no contexto de um contrato de aluguel. (BVerfGE 84, 192, Interdição). O Tribunal de Justiça de Regensburg decidiu que, pelo fato de o locatário ter ocultado sua interdição perante o locador, este teria sido maliciosamente enganado, tendo, portanto, direito à rescisão do contrato (art. 564b, §1, do Código Civil alemão).

Contra essa decisão impetrou o locatário recurso junto ao Tribunal Constitucional com a fundamentação de que seu direito à autodeterminação constitucional teria sido violado, porque o Tribunal de Justiça não considerou o seu interesse quanto ao sigilo da sua interdição.

O Tribunal Constitucional considerou o recurso como fundamentado, destacando a dimensão objetiva do direito geral à personalidade, por meio da qual esse direito também tem efeitos nas relações de Direito Privado, influenciando a interpretação das normas desse ramo. O Tribunal reforçou as consequências prejudiciais para a pessoa que teria que revelar sua interdição: temer-se-ia, sobretudo, uma rotulação social e a impossibilidade de se alugar uma moradia.

No outro caso, tratava-se de um contrato de seguro de vida com um seguro adicional de incapacidade profissional, no qual estava previsto um dever de dispensa da confidencialidade. Segundo o contrato, a segurada perderia seu direito à prestação se ela não concordasse com a dispensa da confidencialidade. A reclamante foi aposentada em 1999 por incapacidade profissional e requereu a prestação derivada do seguro adicional. A seguradora exigiu, para tanto, a concessão de uma declaração que previa o seguinte poder com relação à dispensa da confidencialidade:

[...] buscar informações pertinentes com todos os médicos, hospitais e estabelecimentos hospitalares, nos quais estive ou estarei em tratamento, bem como meu seguro-saúde: [...] e a companhias de seguro, instituições de seguro social, órgãos públicos, empregadores atuais e antigos. Dispenso aqui expressamente sua obrigação em guardar sigilo em relação a essas pessoas e órgãos para os quais tais informações serão solicitadas.

Embora a segurada tenha enviado de volta o requerimento, ela riscara a cláusula referente à dispensa da confidencialidade. No lugar desse poder, geral ela propôs "conceder autorizações individuais para cada pedido de informação". A empresa recusou o requerimento, fazendo com que a segurada ajuizasse uma ação. Todas as instâncias indeferiram a ação da segurada. 
Com o recurso ao Tribunal Constitucional alemão, faz-se valer uma violação do art. $2^{\circ}, \S^{\circ}$, combinado com o art. $1^{\circ}, \S^{\circ}$, da LF. O ponto de partida da decisão é a dimensão objetiva dos direitos fundamentais e seus efeitos no Direito Privado: como decisões constitucionais baseadas em valores, os direitos fundamentais atuam nas relações de Direito Privado por meio dos preceitos do Direito Civil.

Assim, os tribunais têm que garantir a proteção de direito fundamental "por meio da interpretação e aplicação do Direito ordinário" e concretizá-la nos casos individuais. Embora o Tribunal Constitucional não possa corrigir a interpretação contratual dos tribunais especializados, ele deve examinar se a interpretação das instâncias anteriores infringe os conteúdos da proteção dos direitos fundamentais.

O direito à autodeterminação informativa, que garante o poder do indivíduo referente ao fornecimento e utilização dos seus dados pessoais, também age como norma de proteção, ou seja, como direito objetivo no âmbito privado e, nessa medida, deve ser levado em consideração pelos juízes em um caso concreto.

O Tribunal confirma sua declaração anterior da sentença referente ao recenseamento da população, segundo a qual o indivíduo não possui nenhum direito real de domínio sobre determinadas informações, haja vista que ele se desenvolve dentro de uma comunidade social e é dependente de comunicação. Mesmo se "interesses de comunicação de outros" possam restringir esse direito, o indivíduo poderá decidir por si mesmo, a princípio, como ele configura suas relações comunicacionais. Ele deve poder decidir se deseja manter sigilo a respeito de suas informações pessoais ou expôlas. Ambas as formas de conduta são protegidas em termos de direitos fundamentais. Todavia o Tribunal constata que uma autoproteção tem que ser efetivamente realizável:

\footnotetext{
Para tanto, também tem que ser efetivamente possível e exigível para o indivíduo uma autoproteção informativa. Se não for esse o caso, subsiste uma responsabilidade por parte do Estado em garantir os pressupostos da participação na comunicação autodeterminada. Em semelhante caso não pode ser negada ao interessado a proteção estatal, recorrendo-se a uma aparente voluntariedade da exposição de determinadas informações. Pelo contrário, o dever de proteção decorrente do direito geral de personalidade impõe aos órgãos estatais competentes disponibilizar os mecanismos jurídicos de uma autoproteção eficiente.
}

Em seguida, o Tribunal Constitucional alemão se refere ao princípio da perturbação da paridade contratual, expondo que o contrato deveria ser fundamentalmente respeitado como expressão da vontade consensual das partes, a não ser que um dos parceiros tenha "tamanho peso que ele possa determinar unilateralmente de fato o conteúdo do contrato". Nesse caso, a autodeterminação de ambas as partes precisaria ser garantida para que não se converta em determinação por terceiros. Ademais, o Tribunal salienta que a voluntariedade da exposição da informação também poderia ser colocada em dúvida se a prestação oferecida para o indivíduo for de considerável importância. Por fim, o segurado não teria nenhuma alternativa real para a assinatura da declaração de dispensa da confidencialidade para além da não contratação do serviço.

Em sua fundamentação, a Corte constitucional reconhece que é importante para a companhia seguradora examinar a ocorrência do caso que dá direito ao seguro. Por outro lado, a autoproteção do segurado é igualmente importante: para que seu interesse no sigilo possa ser realmente garantido, devem ser dadas alternativas à declaração geral de dispensa da confidencialidade.

Assim, constata o Tribunal Constitucional que um contrato pode prever tal dispensa da confidencialidade ao conceder diversas alternativas para o segurado. Os custos acrescidos devem ser suportados pelo próprio segurado, desde que isto não impeça o exercício do direito.

A referida decisão produziu efeitos visíveis no ramo de seguros. No dia 17 de janeiro de 2012, o Grupo de Düsseldorf [Düsseldorfer Kreis] publicou, juntamente com a Associação de Seguradoras Alemãs, uma declaração-modelo de dispensa da confidencialidade.

Com relação à avaliação do risco e do exame da obrigatoriedade de prestação, evidencia-se na declaração-modelo que o segurado pode escolher entre duas cláusulas contratuais: ele pode dar seu consentimento para a dispensa da confidencialidade de forma geral no momento da celebração do contrato ou posteriormente no caso concreto. São previstas as seguintes possibilidades: 
Desejo que o seguro XY me informe em cada caso concreto de quais pessoas ou instituições é necessária uma informação e para qual finalidade. Irei, então, decidir em cada caso se:

Consinto com a coleta e utilização dos dados referentes à minha saúde pelo seguro $\mathrm{XY}$, dispenso as pessoas ou instituições citadas bem como seus funcionários de seu dever de guardar sigilo e consinto na transmissão dos dados referentes à minha saúde para o seguro $X Y$

Ou se eu apresentarei os documentos necessários

É de meu conhecimento que isto pode levar a um atraso no processamento do requerimento ou do exame da obrigatoriedade da prestação.

Em princípio, a decisão do Tribunal Constitucional é de grande relevância. Primeiramente, porque o Tribunal afirma a eficácia do direito à autodeterminação informativa no âmbito das relações entre particulares ao aplicar esse direito como norma objetiva em um litígio privado. Assim, se transforma paulatinamente a concepção cunhada na sentença referente ao recenseamento, segundo a qual o direito à autodeterminação informativa teria efeito primordial na relação entre Estado e cidadãos.

Em segundo lugar, a importância da decisão reside no fato de que o Tribunal Constitucional avalia as necessidades de proteção no caso de consentimento aparente ou fictício em razão de desequilíbrios de poder, não apenas quando se está aplicar o princípio da autonomia privada no direito obrigacional, mas também no tocante ao direito à autodeterminação informativa, ou seja, no contexto de aplicação do direito da personalidade.

Por conseguinte, da dimensão objetiva do direito à autodeterminação informativa decorre não apenas um dever de proteção contra o conhecimento não autorizado por terceiros, mas também um dever de proteção contra o consentimento meramente aparente (ou fictício) quanto ao tratamento de dados. Dos deveres de proteção decorrentes do direito à autodeterminação informativa resulta, assim, um controle judicial específico também de contratos que regulam o tratamento de dados.

\section{Conclusão}

No presente artigo, examinou-se como a jurisprudência do Tribunal Constitucional alemão referente ao livre desenvolvimento da personalidade (art. $2^{\circ}, \S^{\circ}$, da Lei Fundamental alemã), evoluiu continuamente a fim de consolidar a proteção de dados em diversas circunstâncias. Foi também considerado que a interpretação do mencionado artigo, combinado com o art. $1^{\circ}, \S^{\circ}$, da LF, representa a base comum para múltiplas concepções da vida privada no direito alemão; em especial, o amplo e flexível direito geral de personalidade.

Essa constante evolução e as noções a ela relacionadas contribuíram continuadamente para superar os déficits das fórmulas anteriores sem prejudicar a sistematicidade da dogmática constitucional.

A formulação de um âmbito de proteção da esfera privada individual se originou no momento em que o Tribunal constatou as lacunas da sua concepção anterior, a liberdade geral de ação: enquanto a liberdade geral de ação protege a livre ação do indivíduo, ela não possui o condão de protegê-lo contra ações de terceiros (GRIMM, 1997, p. 7). A concepção do direito à proteção da esfera privada se apoia na caracterização de um âmbito que distingue o privado e o não privado. Seu objetivo não é criar um âmbito de isolamento do indivíduo, mas garantir a segurança esperada do caráter sigiloso de dados ou informações designados como "privados". Assim, trata-se, em primeiro lugar, da proteção da confiança, na medida em que aquilo que é entendido como privado permanece protegido contra a divulgação no ambiente externo (GRIMM, 1997, p. 207).

Ainda que a concepção da esfera privada tenha importante papel na jurisprudência constitucional, as críticas à relatividade da esfera privada e ao contexto do uso dos dados evidenciaram seus déficits no contexto da sociedade da informação e ensejaram uma evolução desse conceito. Assim, surgiu o direito geral de personalidade. Todavia é importante notar que, na jurisprudência do Tribunal Constitucional, a concepção da esfera privada ainda continua a ser aplicada quando se fala do caráter privado de determinadas informações.

Contrariamente à fórmula da esfera privada, o direito geral de personalidade se desenvolveu, sobretudo, de modo abstrato e combinado com a ideia de autodeterminação pessoal. Ele é concebido em um nível 
abstrato que, de um lado, oferece uma proteção mais abrangente e, de outro, abarca o conceito do poder de autodeterminação. Como o direito da personalidade não possui um conteúdo fixo, ele é capaz de oferecer proteção diferenciada de acordo com a intervenção na vida privada. Logo, sua abstração se torna sinônimo de adaptabilidade, o que consiste na sua contribuição mais relevante.

Pelo fato de o direito da personalidade geral formular a posição jurídica como poder de decisão individual, tornou-se mais simples, na sentença relativa ao recenseamento da população, reestruturar a proteção de direito fundamental, orientada para a informação, por meio da criação de um direito à autodeterminação informativa (GRIMM, 1997, p. 15). Assim, esse direito herda as propriedades do direito da personalidade geral, mais precisamente: a abstração, a forma procedimental e a associação com a concepção de autodeterminação.

Logo, da mesma forma que no direito geral de personalidade, a relevância da autodeterminação informativa reside na flexibilidade oportunizada por uma concepção asbtrata de proteção, pois se reporta ao poder de decisão do indivíduo, oferecendo grande flexibilidade (ALBERS, 2005, p. 236). Por não possuir um conteúdo fixo de garantia, o direito à autodeterminação informativa pode ser aplicado a uma multiplicidade de casos envolvendo a coleta, processamento ou transmissão de dados pessoais. Adicionalmente, o direito à autodeterminação informativa representa uma proteção mais ampla, porque não está mais limitado às informações pertencentes à esfera privada (ALBERS, 2005, p. 236).

Por fim, a autodeterminação informativa dá uma resposta convincente à abordagem crítica da relatividade da esfera privada, pois se trata exclusivamente do poder do titular do direito, e não mais da atribuição de dados à esfera privada.

À primeira vista, essa concepção facilita a tarefa do aplicador do Direito, que, no primeiro momento, deve realizar um exame puramente formal/objetivo da referência à pessoa e do seu consentimento, em vez de realizar uma análise tendencialmente subjetiva. Mas, de fato, a subjetividade da análise cresce quando são analisados os limites do direito a fim de se esclarecer a existência de um interesse geral preponderante ou não. (BVerfGE 65, 1 (44), Recenseamento).

Assim, a história da proteção de dados na Alemanha somente pode ser explicada de forma adequada quando considerada no contexto da anterior concepção da proteção da esfera privada. O surgimento do direito à autodeterminação informativa exige a superação da proteção da esfera privada e pode ser compreendido, por isso, por meio de um processo de abstração do conteúdo da proteção (GRIMM, 1997, p. 13; ALBERS, 2005, p. 232). Daí decorre que a gênese do direito à autodeterminação informativa pressupõe a formalização da proteção da personalidade: o direito se desvia de seu conteúdo material e desloca sua base para um poder de decisão formal e instrumentos procedimentais.

Apesar da concepção primariamente procedimental do direito à autodeterminação informativa, em sua fundamentação da sentença referente ao recenseamento populacional, o Tribunal Constitucional fornece também elementos substanciais, como os riscos concretos à liberdade do indivíduo e limites substanciais do processamento de informações, que recaem em uma relação de tensão com a noção de poder de decisão: a tensão entre controle de dados e riscos da informação (MALLMANN, 1995, p. 30).

A questão a respeito de como o quadro jurídico para a proteção individual pode ser realizado, no tocante ao tratamento de dados e informações, continua a ser cunhada pela ambivalência evidenciada pela sentença do Tribunal relativa ao recenseamento: por um lado, há a abordagem de proteção procedimental, isto é, que se orienta pela decisão do interessado e revela um caráter individual; por outro, há a concepção que se fixa nos riscos decorrentes do uso das informações, aplicando conceitos substanciais e exigindo limites em determinados casos. ${ }^{10}$ Trata-se de tensão entre o conceito puramente formal de privacidade,

10 Esta tensão é nítida na abordagem de esfera privada formulada por Mallmann (1995, p. 30): "Consequentemente, esfera privada deve ser definida como um âmbito distinto, de acordo com o grupo de interesses individuais e sociais, de não informação sobre indivíduos. A decisão sobre informação ou não informação, i.e., sobre a respectiva admissibilidade do processamento de informações, não pode ser tomada nem a princípio pelo titular dos dados- para o que aponta, porém, a concepção de direitos à autodeterminação informativa - nem unicamente pelos interessados na informação - o que amplamente corresponde à prática atual. [...] Mas uma esfera privada assim compreendida está amplamente desprovida de critérios de conteúdo. Ela sinaliza, primeiramente, apenas a necessidade de uma estrutura de informação social diferenciada. A privacidade só ganha contornos com base em uma análise que deve atestar quais interesses individuais ela deve proteger contra quais riscos". 
em que apenas a decisão e a vontade do interessado têm um papel a desempenhar, e outro conceito mais objetivo, no qual a situação objetiva de risco individual também ganha importância. ${ }^{11}$

\section{Referências}

ALBERS, Marion. Informationelle selbstbestimmung. Baden-Baden: Nomos, 2005.

ALBERS, Marion. Zur Neukonzeption des grundrechtlichen Daten“schutzes. In: HARATSCH, A.; KUGELMANN, D.; REPKEWITZ, U. (coord.). Herausforderungen an das Recht der Informationsgesellschaft: 26. Tagung der Wissenschaftlichen Mitarbeiterinnen und Mitarbeiter der Fachrichtung Öffentliches Recht. Stuttgart: Boorberg, R, 1996. p.113.

BASTON-VOGT, Marion. Der sachliche Schutzbereich des zivilrechtlichen allgemeinen Persönlichkeitsrechts. Tübingen: Mohr Siebeck, 1997.

BENDA, Ernst. Privatsphäre und persönlichkeitsprofil. In: LEIBHOLZ, G.; FALLER, H. J.; MIKAT, P.; REIS, H. (coord.). Menschenwürde und freiheitliche Rechtsordnung. Festschrift für Willi Geiger zum 65. Tübingen: Mohr Siebeck, 1974. p. 23.

BULL, Hans Peter. Informationelle Selbstbestimmung: vision oder illusion? Datenschutz im Spannungsverhältnis von Freiheit und Sicherheit. 2. ed. Tübingen: Mohr Siebeck, 2011.

GRIMM, Dieter. Persönlichkeitsschutz im Verfassungsrecht. In: LORENZ, E. (coord.). Schutz der Persönlichkeit: Mit Vorträgen von Dieter Grimm und Peter Schwerdtner. Karlsruhe:

Versicherungswirtschaft, 1997.

HUBMANN, Heinrich. Das persönlichkeitsrecht. 2. ed. Colônia: Böhlau, 1967.

JARASS, Hans D. Das allgemeine persönlichkeitsrecht im Grundgesetz. Neue Juristische Wochenschrift, 14, 1989, p. 857.

JARASS, Hans D. Die Entwicklung des allgemeinen Persönlichkeitsrechts in der Rechtsprechung des Bundesverfassungsgerichts. In: ERICHSEN, H. U.; KOLLHOSSER, H.; WELP, J. (coord.). Recht der persönlichkeit. Berlim: Duncker \& Humblot, 1996. p.89.

KUBE, Hanno. Persönlichkeitsrecht. In: ISENSEE, J.; KIRCHHOF, P. (coord.). Handbuch des Staatsrechts der Bundesrepublik Deutschland. Freiheitsrechte: Heidelberg, 2009. v. 7.

MALLMANN, Otto. Zielfunktionen des Datenschutzes. Schutz der privatsphäre. Korrekte Information. Frankfurt am Main: Luchterland, 1995.

MARTINS, Leonardo (org.). Cinqüenta anos de Jurisprudência do Tribunal Constitucional Federal Alemão. Montevideo: Konrad Adenauer Stiftung, 2005.

MÜCKENBERGER, Ulrich. Datenschutz als Verfassungsgebot. Das Volkszählungsurteil des Bundesverfassungsgerichts. Kritische Justiz,, 17, I, 1984, 1.

PODLECH, Adalbert. Das Recht auf Privatheit. In: PERELS, J. (coord.). In Grundrechte als Fundament der Demokratie. Frankfurt am Main: Surhkamp, 1979, p.50.

SCHLINK, Bernhard. Das Recht der informationellen Selbstbestimmung. Der Staat, 25, 1, 1986.

SCHLINK, Bernhard. Die Amtshilfe: Ein Beitrag zu einer Lehre von der Gewaltenteilung in der Verwaltung. Berlim: Duncker \& Humblot, 1982.

STEINMÜLLER, Wilhelm; LUTTERBECK, Bernd; MALLMANN, Christoph; HARBORT, Uwe; KOLB, Gerhard; SCHNEIDER, Jochen. Grundfragen des Datenschutzes. Gutachten im Auftrag des Bundesministeriums des Innern. BTdrucks VI/3826, anexo 1, 1971. 
TRUTE, Hans-Heinrich. Verfassungsrechtliche Grundlagen. In: ROßNAGEL, A. (coord.). Handbuch datenschutzrecht: Die neuen Grundlagen für Wirtschaft und Verwaltung. Munique: C.H. Beck, 2003, p. 156.

Recebido em: $24 / 4 / 2020$

Aprovado em: 08/05/2020 